\title{
A FORTRESS BETWEEN ARTIFICE AND NATURE: THE LASER SCANNING SURVEY OF THE CASTLE OF PESCOPAGANO AS AN INSTRUMENT OF KNOWLEDGE, CONSERVATION AND ENHANCEMENT
}

\author{
A. Pane ${ }^{1, *}$, R. Catuogno ${ }^{1}$, M. Facchini ${ }^{1}$, L. Morano $^{1}$ \\ ${ }^{1}$ University of Naples Federico II - (andrea.pane, raffaele.catuogno, marco.facchini)@unina.it, lucia.morano95@gmail.com
}

Commission II - WG II/8

KEY WORDS: Castle, Survey, Laser scanning, Conservation, Pescopagano, Basilicata, Italy.

\begin{abstract}
:
The castle of Pescopagano, a small village located on the border between Basilicata and Campania, is a complex of great historical and landscape value, for the inseparable combination that binds its stones to the rock where it stands. Founded perhaps in the Byzantine times, but certainly renovated and built in its current forms between the 11th and 12th century, the castle had considerable military importance under Frederick II of Swabia. Seriously damaged by the earthquake of 1694, the fortress underwent a partial reconstruction, but ended up suffering further collapses caused by the Irpinia earthquake of 1980, such as to motivate the first interventions of securing and, above all, the application of the listing process. Today the castle is still largely in ruins and is only partially accessible thanks to a limited intervention on the paths. The present research aims at deepening the knowledge of the state of conservation, the damage mechanisms and the previous restoration interventions of the castle, in order to define possible strategies for its restoration and enhancement. The analysis work uses the most advanced laser scanning and drone detection systems, in order to document, as accurately as possible, the complex patrimonial system of the castle. Thanks to the combined use of these techniques, the objective is also to define methods that can be replicated in other contexts where the relationship between geomorphology and construction is so relevant that it jeopardizes the use of any other traditional survey system.
\end{abstract}

\section{INTRODUCTION}

In the wide field of architectural heritage, the knowledge of complex buildings such as castles and fortified structures has benefited, more than other types of artefacts, from the significant technological advances of the last decades. Buildings often inaccessible due to morphological or historical conditions, or that present conditions of high risk for collapses and other natural disasters, can today be investigated in conditions of relative safety, without renouncing to the accuracy of the analysis but, indeed, pushing knowledge far beyond the levels that were considered acceptable only two decades ago. This is precisely the case of Pescopagano, a small village in southern Italy, located on the border between Basilicata and Campania, whose castle, placed in a prominent position on a natural relief that crowns the village, constitutes a complex of great historical and landscape value for the inseparable combination that binds its stones to the rock where it stands, but also an object of difficult knowledge due to its conditions of partial inaccessibility.

The study of the Pescopagano castle was carried out with the aim of deepening the knowledge of its state of conservation, its damage mechanisms and its previous interventions, in order to define possible conservation and enhancement strategies. The analysis work used the most advanced laser scanning and drone detection systems, matched together in order to document the complex heritage system of the castle as accurately as possible. At the end of this work, a proposal for compatible conservation and reuse was also made, preserving the suggestive condition of ruin which has been stratified for centuries.

\section{THE "CASTRUM PETRA PAGANA": A HISTORICAL OUTLINE}

\subsection{The toponym Petra Pagana}

The term Pescopagano contains several meanings and references, but no official translation has been advanced so far. Therefore, it is necessary, first of all, to analyze its two components: 'pesco' and 'pagano'.

As for the term 'pesco', it derives from piesco or piescone, in Latin petra, a large rock or stone, a term still used today in the local dialectal language. This expression refers both to the morphological conformation of the place and to the medieval meaning with which a castellum built on a hill was commonly indicated, from which Pescopagano, Piescopagano and Petra Pagana.

On the other hand, the discussion on the term 'pagan' is more complex. It was probably added in 1343, following the detachment of the castle of Petra from the city of Conza, being its former barbican castrum, that is the first bulwark and defense in case of enemy attacks. In this regard, among the numerous hypotheses, the most likely is the one that considers the word 'pagan' as pagus (village, hamlet), indicating, since Lombard, a marginal part of the city. It is therefore probable that we are referring to that part of the territory that, after the sale, was separated from the vast area of Conza, becoming a real independent village (Gattini, 1910, p. 61-62; Laviano, 1926, p. 128-129).

\footnotetext{
* Corresponding author
} 


\subsection{The genesis of the village}

There are many irrefutable testimonies that confirm the ancient origin of the city of Pescopagano, including the discovery, during some demolition works, of a sculpture depicting Giano Bifronte and thus confirming the existence of an inhabited center already in Roman times. A second testimony is provided by the analysis of the surviving wall facings of the castle, made of opus incertum, located in the oldest and overlying part of the fortress. Further evidence of the existence of the fortress in ancient times is provided by the historian Agathias Scholasticus, according to whom, during the Gothic war (553 AD), the only place capable of welcoming the surviving soldiers was a castle protected by boulders eroded by a torrent - the Guana - which flows downstream from the village of Pescopagano (Agazia Scolastico, 1660, p. 52-54; Araneo, 1930, p. 14-35; Mancini, 1967).

\subsection{The castle in the first official documents}

The first original information related to the city is reported in one of the most important official documents of the time, the Catalogus Baronum, written in the mid-12th century to describe and identify the numerous fortified places of the Kingdom with its feudal lords. From this manuscript it can be deduced that the castrum belonged to a certain Count Jonathas, who, in 1161, together with the farmhouse of Sant'Andrea, donated the fort to the archiepiscopal mess in Conza (Jamison, 1972, p. 122-123, p. 150; Borianovi, 1978, p. 198-199).

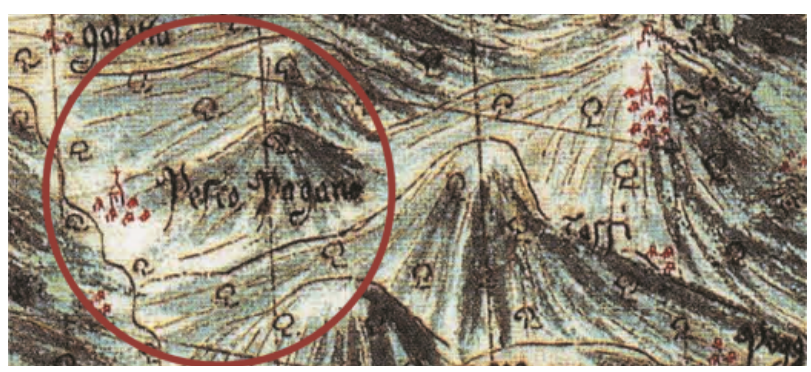

Figure 1. Bibliothèque Nationale de France, Cartes et Plans, GE AA 1305, T1a.1.

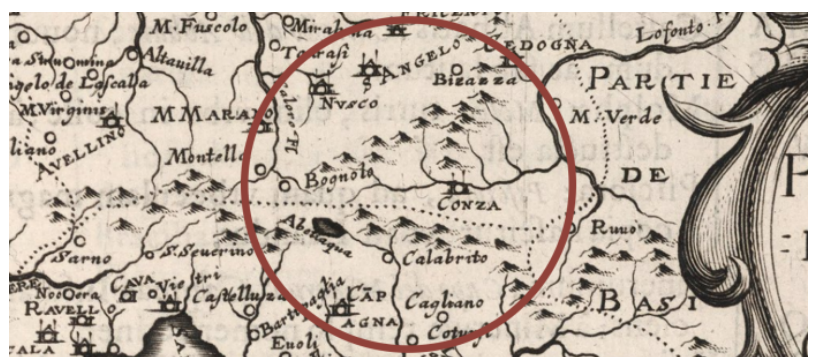

Figure 2. Montecarlo da Montecalerio G., 1649. La Principauté et la Capitanate.

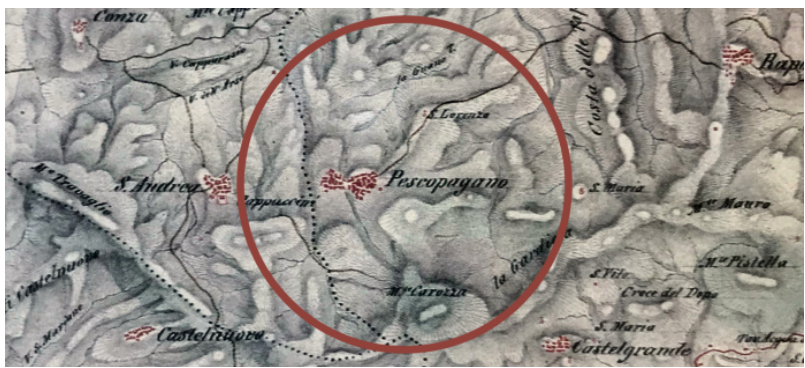

Figure 3. Principe I., 1989. Cartografia storica di Calabria e di Basilicata, Mapograf, Vibo Valentia, p. 290.
About a century later (1239) Pescopagano is mentioned in the most famous Statutum de reparatione castrorum by Frederik II of Swabia as part of the reorganization of the royal castles, according to which its inhabitants - together with those of the neighboring villages - had to carry out the maintenance and conservation of the castle (Winkelmann, 1888; Sthamer, 1914).

Due to its proximity to important cities where political or religious power resided, the village appears rarely and marginally in the surveys of the area (Fortunato, 1968, p. 145). One of the most accurate cartographies where the castrum (Pesco Pagano) is indicated is part of the three Aragonese maps preserved in the Bibliotheque Nationale de France, thanks to which it can be deduced that in the 15 th century Pescopagano was a medium size village. However, there is no mention of the fortress, nor of its walls. Although, the hamlet of Pescopagano does not appear in most of the cartographies of the 16th century (Figures 1, 2 and 3).

\subsection{The decline of the castrum}

During the 17th century, Pescopagano, which had then become a marquisate thanks to the advent of the D'Andrea family, reached its maximum territorial expansion by incorporating nearby towns within its borders. It passed, in less than a century, from about 300 to over 2500 inhabitants (Capano, 1987, p. 25-26; Martone, 1928, p. 115-116).

Despite the numerous famines and epidemics that followed one another in those years, the real setback came with the sudden earthquake of 1694, which destroyed the entire center and brought down the highest and oldest part of the castle. Since then the castrum has no longer been used, thus becoming a simple inaccessible ruin. These conditions are documented in a postcard of the early 20th century already representing the castle in a condition of ruin (Figure 4). The first information related to the protection and conservation of the castle is provided by the phonograms and requests for authorization registered by the Superintendence of Archaeology, Fine Arts and Landscape of Basilicata. Due to the numerous landslides and to the dangerous collapse of rocky material from the slopes of the castle, in 1976 the Municipal Administration, having recognized the historical and artistic characteristics of the monument, requested the partial and limited demolition of the unstable walls, excluding however any type of reconstruction. Four years later, after the violent earthquake of 23 November 1980 that also affected the Lucanian village, producing very serious damage, the Superintendence planned some detailed surveys of the castle, from which it emerged that its walls had long been abandoned and did not present imbalances or failures due to sudden causes, but to the lack of maintenance and to the action of time (Figure 5).

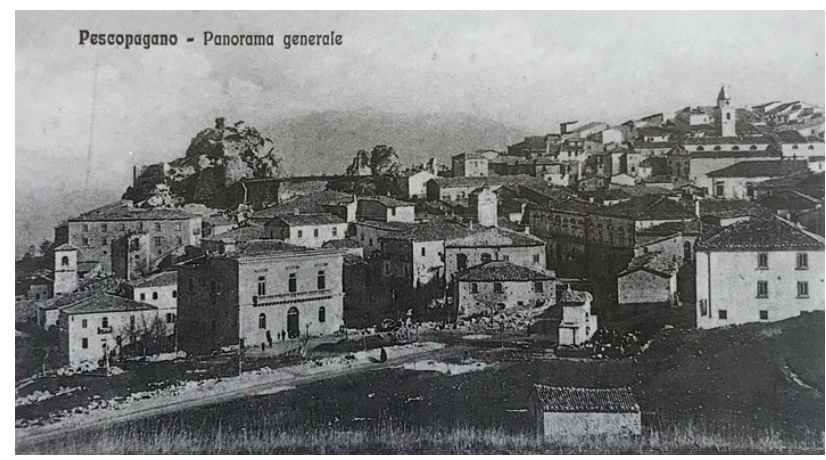

Figure 4. General panorama of the municipality of Pescopagano with the ruined castle. Date of the postmark: 19/08/1914 (Luccioni, 1988, p. 37). 

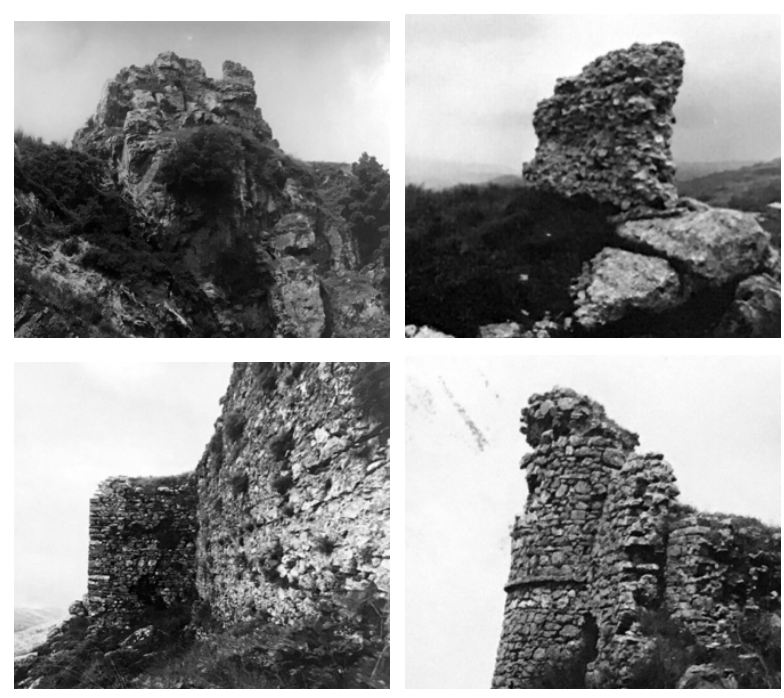

Figure 5. Remains of the castle photographed on 20th May 1980, six months before the devastating earthquake (contact prints $n$. 4-5-8 contained in the archive $\mathrm{M} / \mathrm{PZ} / 57 / \mathrm{F}$ of SABAP).

Although in ruins, in 1981 the Pescopagano castle, in accordance with the protection law of 1st June 1939 n. 1089, was listed for «its historically glorious past for the various dynasties of feudal principles that had it» ${ }^{1}$. Currently the castrum- whose ruins are of municipal property, while the adjoining garden belongs to private citizens - is inaccessible and closed to the public, despite attempts to reopen the site in recent years.

\section{THE SURVEY}

The research activity aimed at a scrupulous work of data collection in order to return rigorous orthographic representations of the castle and its context. Given the partial inaccessibility of the stronghold, in the part facing north on a cliff more than 50 meters deep, the complete digital restitution was only possible thanks to the integration of data obtained from two survey methodologies: the photogrammetric survey - with the use of a drone equipped with a camera - and the laser scanning survey .

\subsection{Photogrammetric survey}

The choice to proceed with a photogrammetric survey with a drone stems from the morphology of the soil and the impossibility of reaching and analyzing every single part of the building, but also and above all from the need to have an overall view of the hill and its relationship with not anthropized nature, to the north, and the inhabited center, to the south. The image-based technique used is photogrammetric modeling, which, using Structure-fromMotion (SfM) algorithms, reconstructs a point cloud composed of coordinate points obtained from the epipolar interpolation of pixels with similar characteristics in two frames acquired in succession. For the Castle of Pescopagano, the acquisition of the frames was organized using a flight planning software, establishing a GSD (Ground Sample Distance) of $1.20 \mathrm{~cm} / \mathrm{px}$, using a UAV (unmanned aerial vehicle) equipped with a photographic objective DJI FC6310S, with focal length of 8.8 $\mathrm{mm}$. During five pre-planned flights 445 photographs were taken, with a longitudinal overlap of $70 \%$ and a lateral overlap (side-lap) of $60 \%$. Of these flights, the first had the nadiral camera, while the other with a 45-degree inclined camera in order to also be able to detect the elevations and the rocky walls.

1 These are the words used by the art historian Roberto Faggella in the document titled Castello: Pescopagano 12-09-1980 in the SABAP archive.
Once the field work was completed, the restitution and elaboration of the three-dimensional model continued through the Agisoft Metashape software, a photogrammetric modeling software that through the featured recognition algorithms (SIFT) can automatically identify, in the frames, the key points (tie points). The processing takes place through four phases: Structure-from-motion (SfM), in which the software aligns the frames by determining the internal orientation parameters and generates the scattered cloud; Multiview Stereo Reconstruction (MVS), in which the software densifies the scattered cloud; Mesh reconstruction, where, through the meshing of the dense cloud, the software generates the model; Texturing, in which the software orthorectifies the images and projects them onto the mesh, returning the rendered model (Figure 6) (Remondino, Zhang, 2006).
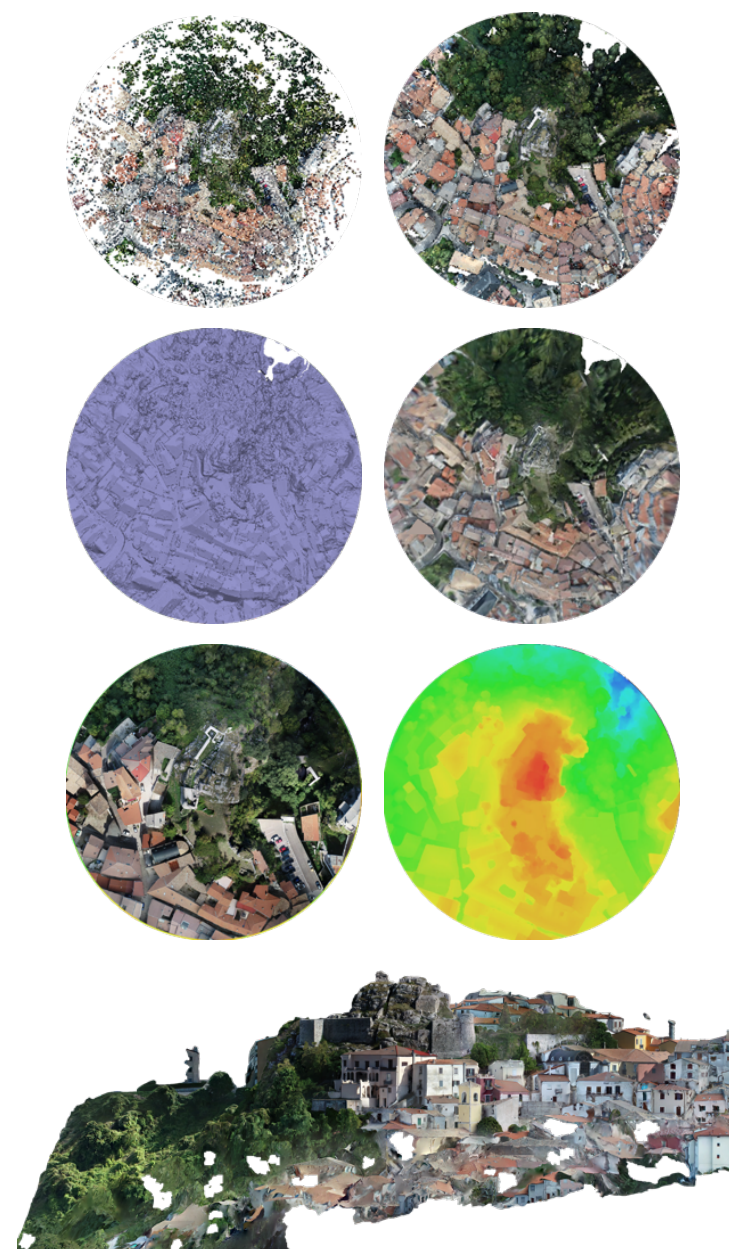

Figure 6. From the left: point cloud, dense cloud, solid, tiled model textured, DEM, ortomosaic, elevation rendered through Agisoft Metashape.

\subsection{Laser scanning survey}

The photogrammetric restitution did not allow the acquisition of portions of the artefact not visible by the drone, therefore the data were integrated with TLS (terrestrial laser scanner) survey. Through the acquisition of range-based point clouds, it was possible to compensate for the gaps in the image-based point cloud. The photogrammetric survey was then integrated by an instrumental survey with a CAM2 Faro Focus 3D X330 Laser Scanner, with an integrated digital camera equipped, with an optical axis coaxial to the laser measuring beam, and with Phase Shift laser scanner technology. 
Thanks to the laser scanning technique it is possible to acquire information relating to planimetric and altimetric data with a single spatial reference system. The result of the acquisition is a set of points whose Cartesian geometric coordinates are then obtained. Given the complexity of the artifact, 34 scans were carried out, lasting 6 minutes each, with a resolution of $6 \mathrm{~mm}$ between two points hit on a plane 10 meters from the emitter setting a $3 x$ quality (each point was beaten 3 times). The result of each individual scan is a point cloud that contains topological and colorimetric information, in addition to the reflectance values for each point acquired. Using the Faro SCENE software, the scans were acquired, identifying at least three reference points in each of them (Figure 7). The sections elevations related to the castle were extracted from the overall point cloud (Figure 8).
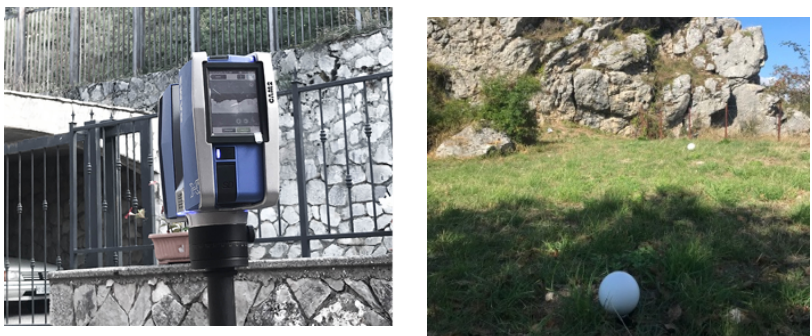

Figure 7. Laser scanner and target.

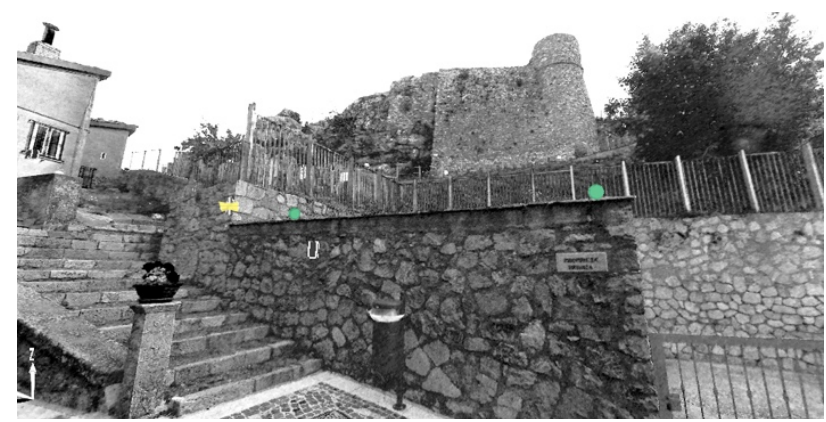

Figure 8. Position of the reference objects within the scan 02 (screenshot of the program Faro SCENE).

\subsection{Matching project}

The laser scanner survey provided very high quality of data; however. it was not possible to scan the entire castle, especially in its upper parts or in the areas on the limestone escarpment. On the contrary, photogrammetry allowed to reach every point of the fortress and a large part of the surrounding ancient urban settlement (Figures 9 and 10). Using a topographical base consisting of 6 GCP (Ground Control Point), a structure has been created to integrate the two reliefs.

The integration between the two methodologies was therefore essential to obtain the complete survey of the entire complex. For the matching of the two projects, during the setting phase RAD targets have been placed along the GCP area (Ground Control Point), in order to be first photographed by the drone and subsequently acquired by the scanner. Six have been identified within the point cloud and in the model obtained by the laser (Grussenmeyer et al., 2008).
With the Agisoft Metashape program, markers were assigned to each point, while with Faro SCENE the coordinates of each of them were identified. The result was an overall and georeferenced point cloud (Figure 11).
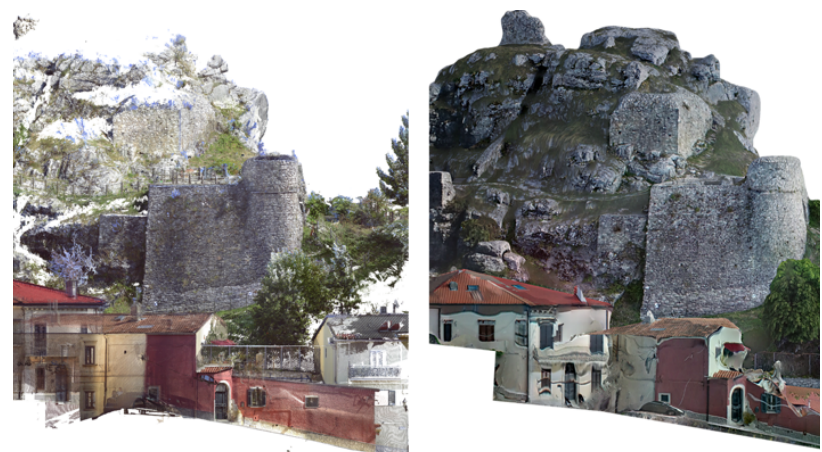

Figure 9. To the left: elevation of the Angevin tower in the laser scanner scans.

Figure 10. To the right: prospect of the Angevin tower in the point cloud obtained with photogrammetric survey.

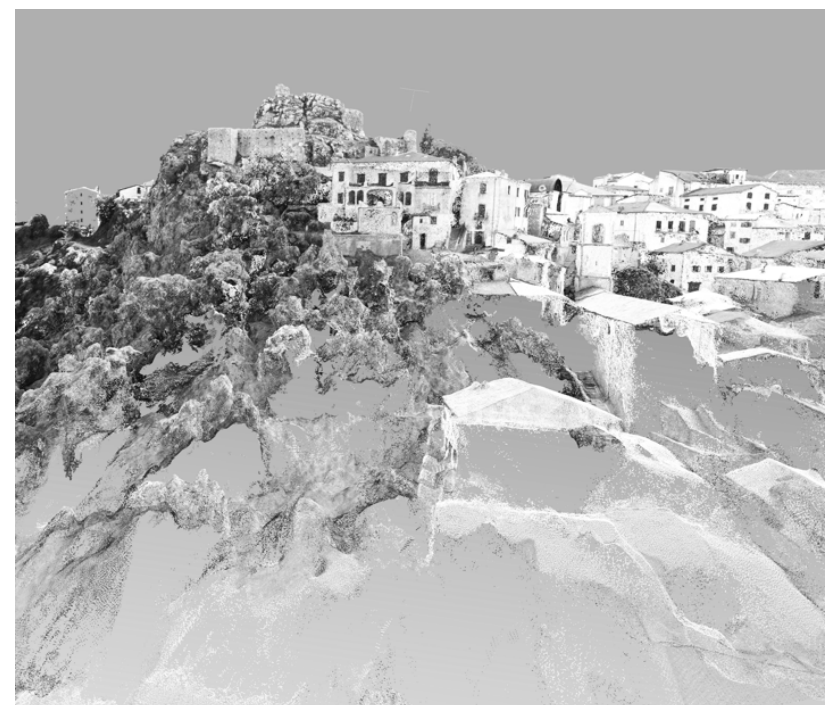

Figure 11. The castle and the hamlet in Point tools.

\section{CONSERVATION AND ENHANCEMENT ISSUES}

The thorough historical research and the phase of critical survey laid the foundations for a subsequent phase of knowledge focused on the surviving medieval elements of the castle. The analysis conducted on the Angevin keep are shown as an example of the entire work.

\subsection{The Angevin circular tower}

The part of the castrum that houses the southeastern tower is the most preserved area of the entire complex. It is a clear testimony of the Angevin era (1266-1442), also remodeled in the Aragonese era (1442-1501), when its height was considerably reduced, and it was equipped with a stone torus (Figure 12). 


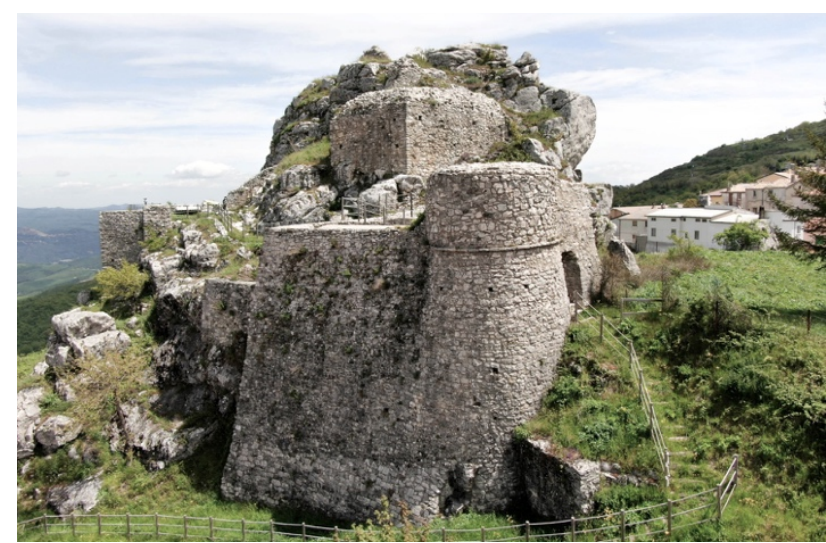

Figure 12. The Angevin tower (photo by UAV of 11/05/2019).

4.1.1 The analysis: For an in-depth knowledge of the tower, it was essential to determine its construction history through an accurate stratigraphic investigation (Boato, 2008). The physical and chronological relationships schematized through the Harris matrix allow to identify not only the escarpment base of the wall as the most ancient unit of the element, but also the capping made after the earthquake of 1980 as the most recent construction (Figures 13 and 14).

This investigation phase has allowed detailed and reasoned geometric and material drawings where, in addition to the scale design of the various elements, it has been identified the different wall textures, the pontoon holes and the modern perimeters (Figure 15).

The studies on the wall facings continued with the definition of the conservative state of the surfaces, including the identification of materials, and alteration and degradation phenomena. The main pathologies have been identified and reported according to the terminology established by the UNI - Nor.Ma.L. 11182 of 2006 (Figure 16). With the awareness that a series of causes with different incidence contribute to the alteration and degradation of the building, it is necessary to understand how to manage the knowledge of the phenomena in order to present effective conservation strategies. In particular, for the large areas affected by phenomena of chromatic alteration or surface deposit an initial manual cleaning was hypothesized, followed by a mechanical one using an atomized water system.

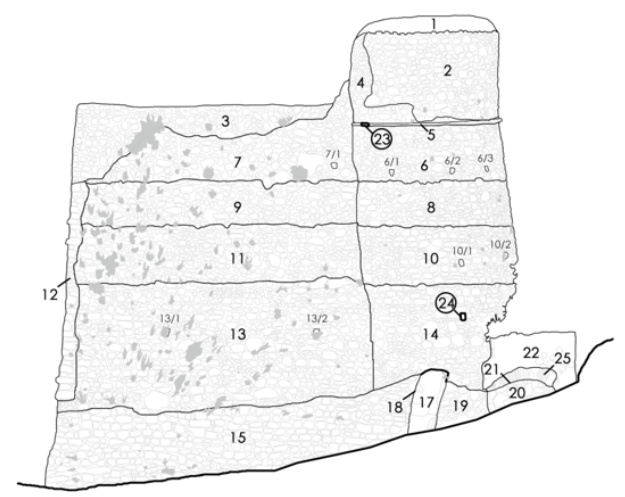

Figure 13. Geometric elevation of the Angevin tower on which the stratigraphic units have been identified.

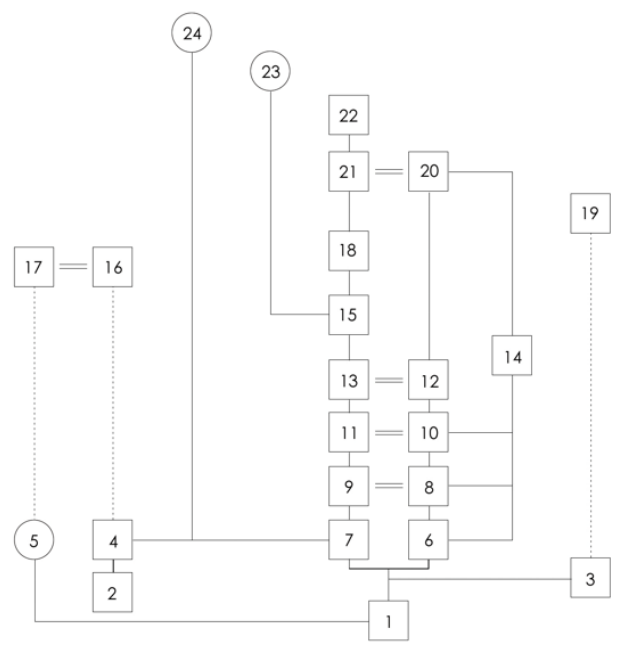

Figure 14. Harris matrix.

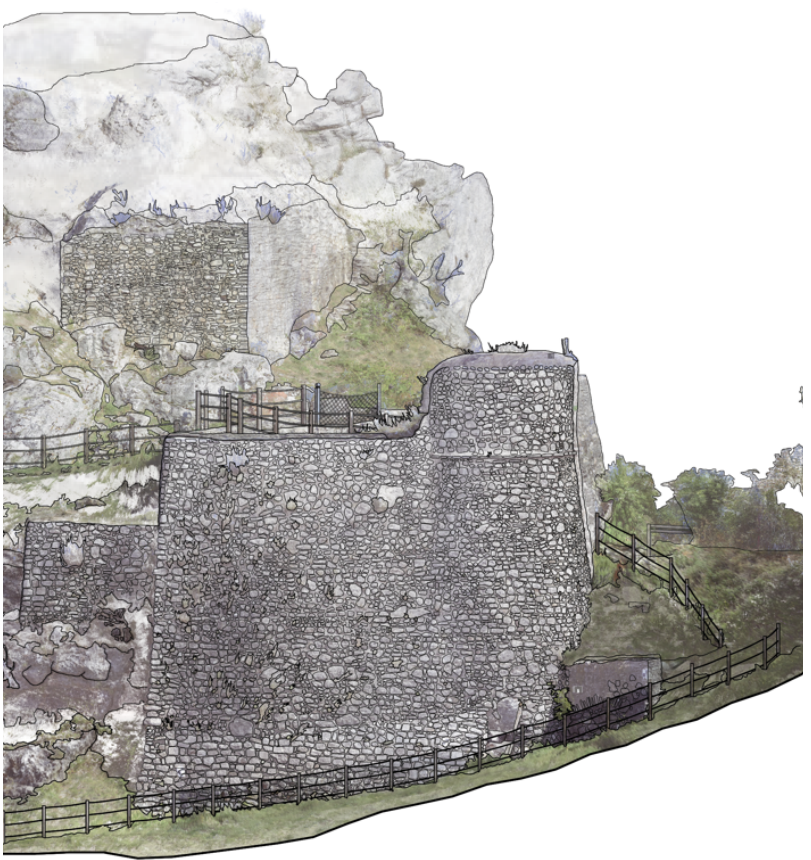

Figure 15. Survey of materials.

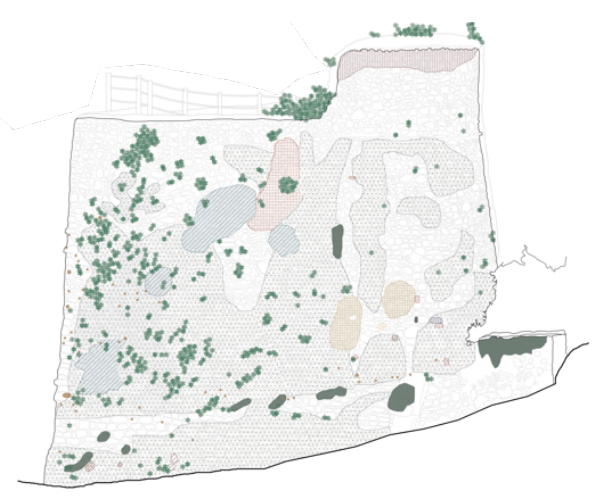

Figure 16. Survey of degradation phenomena. 


\subsection{The conservation project}

The general objective of the conservation project is to keep the charm of the ruin as unaltered as possible, respecting the delicate balance between artifice and nature. This is accomplished by limiting consolidation and repair interventions to a minimum, in accordance with the guidelines that have been spread for several decades in Italy and Europe. Such guidelines on the one hand consider the need to look to ruins mainly as historical documents, and on the other pay particular attention to their relationship with the surrounding landscape (Fancelli, 2006; Oteri, 2009; Marino, 2019).

At the same time, however, it is necessary to proceed to a more in-depth knowledge of the site and its historical phases, through an archaeological excavation, which - preceded by appropriate preliminary investigations based on the use of the G.P.R. (Ground Penetrating Radar) - could reveal further aspects of a story so far investigated mainly thanks to indirect sources. After this phase and the results that it would entail, with the probable highlighting of new hidden structures - it is therefore expected to implement a set of interventions focused on the physical conservation of the building. These include: weed removal operations; elimination of surface deposits; cleaning of all wall facings (with techniques that include both atomized water and manual cleaning with soft brushes); protection of the wall crests and partial closure of the scaffolding holes, reducing their depth to a few centimeters, so as to discourage birds nesting.

Finally, a topic that deserves a separate discussion is the consolidation of the escarpments on which the castle stands, exposed to landslides also in the past. The stabilization of this system is fundamental, both to ensure the conservation of the artifact and to allow its use in conditions of safety. It has been planned a differentiated intervention according to the different areas surrounding the castle: a more contained action for the area that allows the access to the ruins (where the slopes are contained within a 10\% inclination), and a more extensive one in the concentrated escarpments of the north (at the foot of the Swabian tower) and east areas (near the Guana stream). The techniques used belong to the field of naturalistic engineering and, in the first case, consist in the simple coating with grassy species that improve the water and heat balance of the slopes. In the other two cases, the planned interventions are more extensive and have a stabilizing function: they consist in the sowing of shrub species along the north slope and the creation of a proper fascinate system along the east slope. The latter is made of branches of species with a vegetative faculty, arranged in successive rows about three meters apart.

\subsection{The enhancement project}

The purpose of the proposed interventions is summarized in a series of objectives intended to enhance and encourage the use of the castle by both the inhabitants of the village of Pescopagano castrum and by visitors.

The project aims to identify the potential of the fortress by establishing a close relationship between it and the underlying village, while at the same time involving the inhabitants and the main cultural institutions in the process. The goal is to make the Pescopagano castle an attractive pole, while preserving it in a state of ruin, avoiding the reconstruction of lost parts and musealizing the site. Therefore, the intrinsic potential of the building is exploited, focusing on its visibility, on its landscape and historical value, as well as on its proximity to points for social aggregation and public parking areas.
Moreover, the project offers the user a clear and immediate understanding of the local heritage, with the possible inclusion of pre-established tourist routes and the installation of explanatory plaques inside the village, in order to provide a new interpretation system also through computer platforms.

4.3.1 The design for accessibility: The real issue of the castrum is its partial and complex accessibility, which makes even the simplest activities impossible (Figure 17). The castle enhancement project therefore includes strategies to improve accessibility, optimizing the pedestrian area to the west and refunctionalizing the public parking area to the east.

It is precisely the area to the east that is mostly investigated, where it is hypothesized to create a connection, currently nonexistent, to allow the universal use of the castrum. The garden space, in fact, can be visited independently from the ruins and easily reached through the new mechanical lift that allows to overcome the natural difference in height of 17 meters between the level of the road and that of the garden. Rather than a vertical tower, the project opts for the insertion of an inclined elevator which is well suited to the natural slope of the ridge of about $35^{\circ}$ - that is conceptually similar to funiculars but is designed to be used by a smaller number of people. This choice was dictated by its ease of assembly and management compared to the most common vertical lifts (Agostiano et al., 2011; Pane, 2018).

From a technical and constructive point of view, the inclined lift consists of a cabin - where the main controls for closing and opening the doors are located - made of large glass panels to allow a panoramic view of the surrounding landscape. The cabin, which runs on tracks like those of trains, is set in motion by a lifting rope mechanism, equipped with emergency brakes, with a lenght of about 28 meters (Figures 18, 19 and 20).

Alongside the mechanical ascent system inside the parking area, there is a new and suggestive inclined stone staircase. Built on the eastern limestone ridge of the castle, the ramp has the task of connecting via Roma with the large garden next to the medieval site. Its development, marked by sinuous and soft lines, follows the natural conformation of the cliff, previously consolidated through a system of bundles, fitting harmoniously in an area totally abandoned since the 17 th century.

Composed of six hairpin bends, the graded ramp consists of sloping sections - never more than $10^{\circ}-$ and treads with variable dimensions for a length of about 90 meters. In the areas that allow the suggestive view of the Ofanto valley, the steps are longer, forcing the user to slow down his pace in order to enjoy the view. Instead, where the staircase has the city as its background, the step is shorter, forcing the user to travel at greater speed. Along the route there are wide equipped areas that, taking full advantage of the landscape value of the natural context, act both as a viewpoints and as resting places.

Starting from these considerations, the accessibility project is introduced in a respectful way in a non-anthropized environment, connecting the various areas of the site not in a superficial way, but generating a new dimension of the place itself (Figures 21 and 22).

The key to understand the project is its versatility: in fact, these are interventions that can be transposed throughout the regional and national territory, providing the opportunity to develop economic and social collaborations between different institutions. 


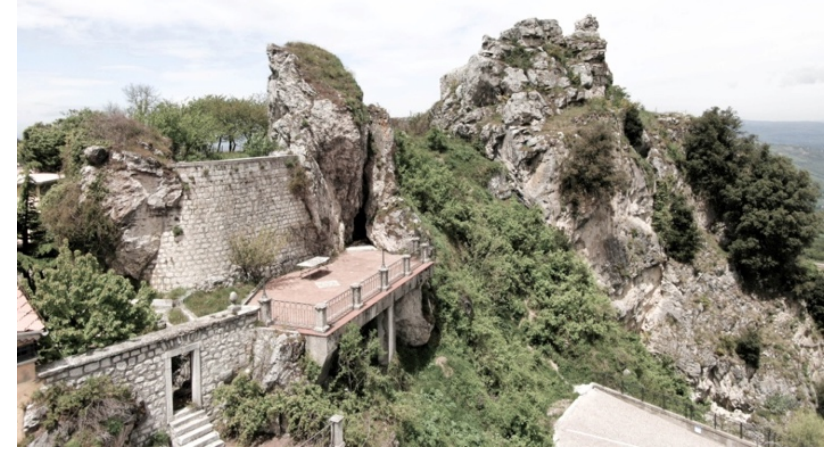

Figure 17. The inaccessibility of East side of the castle (photo by UAV of 11/05/2019).

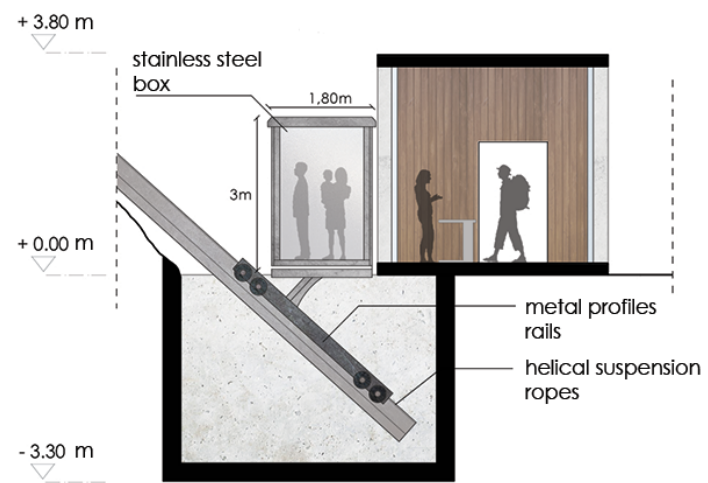

Figure 18. Section on the elevator.

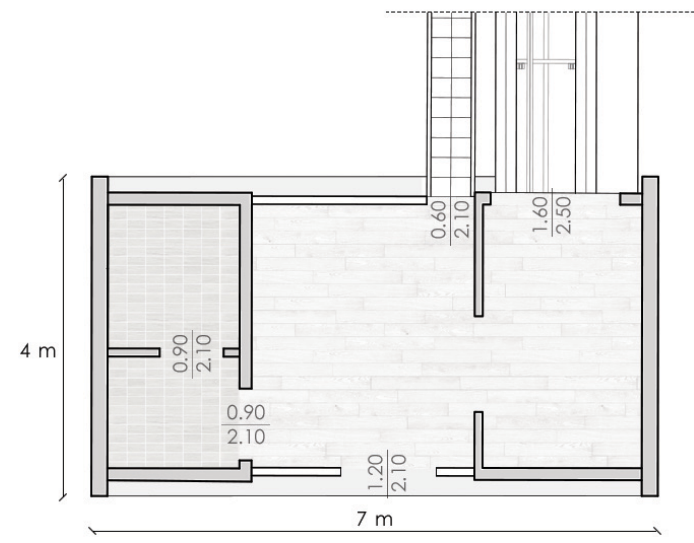

Figure 19. Info point (ground floor).

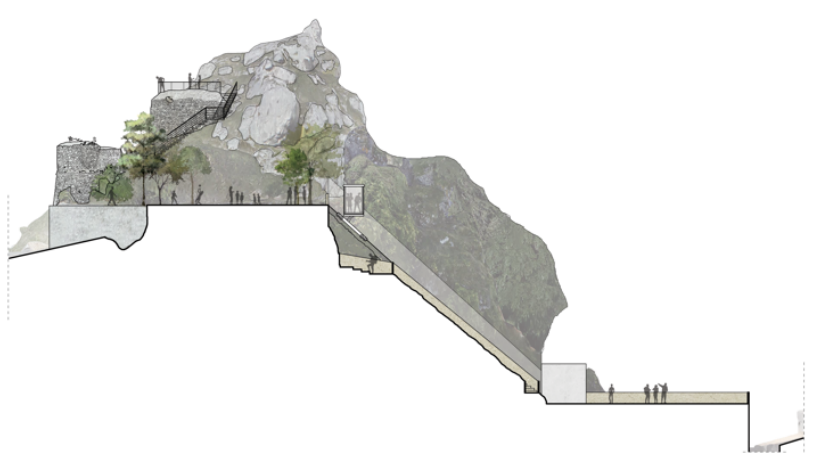

Figure 20. Section on the garden.

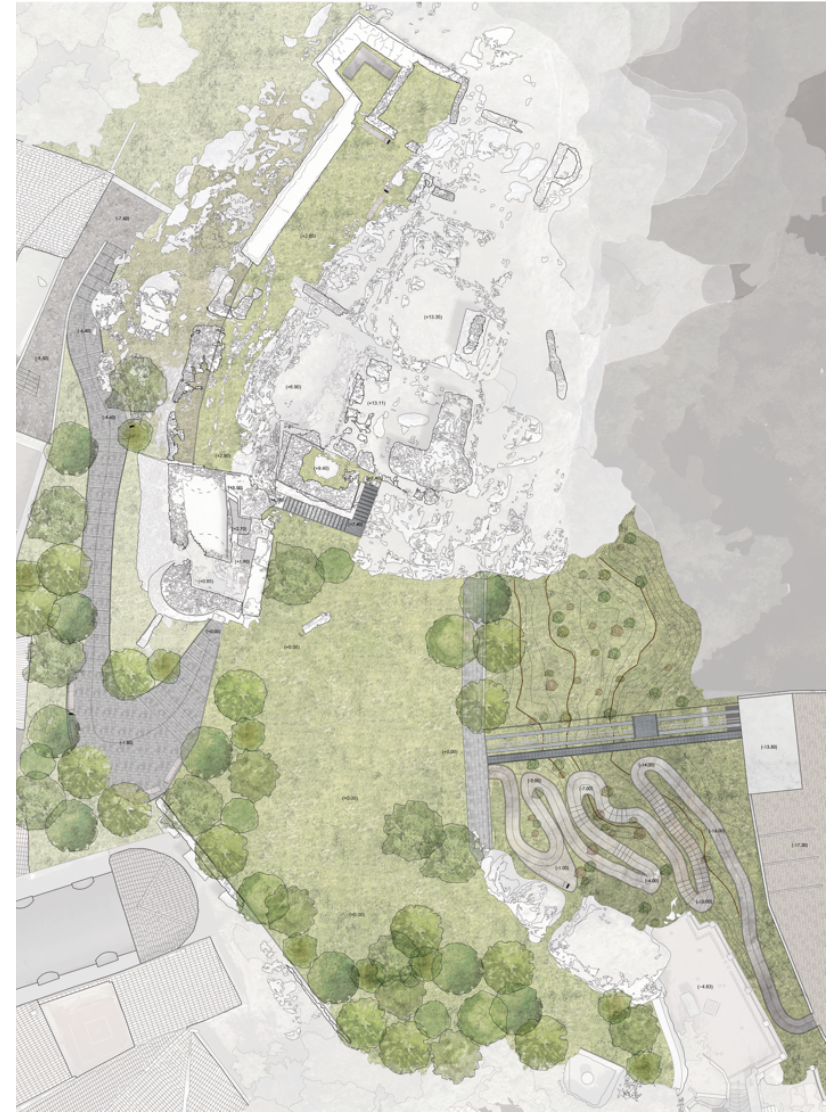

Figure 21. Masterplan.



Figure 22. Accessibility project. 


\section{CONCLUSIONS}

The conservation and enhancement of ruined castles and fortresses, especially those located in the inland and less populated areas of Italy, represent today a great challenge in the field of cultural heritage. The in-depth knowledge of the buildings through a multidisciplinary approach must constitute an unavoidable task to any compatible reuse project of this type of property. In the case of Pescopagano castle, an effective combination of all the most advanced methods for the digital survey of architecture, such as drone photogrammetry and laser scanning, has been tested. These techniques - it must be reiterated - express their maximum potential when they are crossed with other methods of direct and indirect investigation, such as archival research and stratigraphic analysis of the walls, which in the case in question have led to better clarify the succession of the construction phases of the castle. With these premises, the project of conservation and enhancement therefore surpasses any impromptu ambition of form, to act instead as the natural outcome of an in-depth process of knowledge, which maximizes the physical permanence of the artefact and enhances its condition of a ruin integrated with landscape, without renouncing to its compatible use.

\section{ACKNOWLEDGEMENTS}

The present research is part of a Graduate thesis in Preservation of Architectural Heritage, awarded cum laude and recommended for publication by the University of Naples Federico II in January 2020. The thesis was supervised by Andrea Pane, Professor of Architectural conservation, Raffaele Catuogno, Professor of Architectural survey and Marco Facchini, Technical assistant. Although the text is the result of a collective work among the authors, paragraphs 1 and 5 are by Andrea Pane, paragraph 2 by Lucia Morano, paragraph 3 by Raffaele Catuogno and Marco Facchini, paragraph 4 by Lucia Morano and Andrea Pane.

\section{REFERENCES}

Agazia Scolastico, 1660. De imperio et rebus gestis Iustiniani imperatoris, lib. V, Tipografia regia, Parigi.

Agostiano, M., Baracco, L., Pane, A., Vescovo, F., Virdia, E., 2011. Guidelines to overcome architectural barriers in cultural heritage site. Gangemi, Roma.

Araneo, L., 1930. Breve saggio storico sul Comune di Pescopagano, Tipografia S. Pulcrano, Napoli.

Boato, A., 2008. L'archeologia in architettura: misurazioni, stratigrafie, datazioni, restauro. Marsilio, Venezia.

Borianovi, L. 1978. I feudi caudini nel Catalogus baronum. Samnium, 3-4, 198-199.

Capano, A., 1987. Beni culturali nel Marmo-Platano: Muro Lucano, 20 dicembre 1986-31 gennaio 1987: mostra documentaria, Arti grafiche P. Schiavo, Agropoli.

Fancelli, P. 2006. Estetica delle rovine e del paesaggio: la dimensione conservativa. Semantica delle rovine, manifesto libri, Roma, 307-332.

Fortunato, G., 1968. Badie, feudi e baroni della Valle di Vitalba, P. Lacaita, Manduria.
Gattini, C. G., 1910. Delle armi de’ Comuni della Provincia di Basilicata. Tipografia B. Conti, Matera.

Grussenmeyer, P., Landes, T., Voegle, T., Rongle, K., 2008. Comparison methods of terrestrial laser scanning, photogrammetry and tachometry data for recording of cultural heritage buildings. Int. Archives of Photogrammetry, Remote Sensing and Spatial Information Sciences, 37 (B5), 213-218.

Jamison, E., 1972. Catalogus Baronum, Istituto storico italiano, Roma.

Laviano, F. P., 1926. La vecchia Conza e il Castello di Pescopagano, ditta tipografica editrice Vecchi e C., Trani.

Luccioni, L., 1988. La Basilicata ... com'era: aspetti territoriali urbani ed umani della Basilicata in un album di immagini d'epoca, 1896-1945. Atena, Roma.

Mancini, R., 1967. Padre Antonio di Pescopagano, Editrice San Gerardo Maiella, Materdomini.

Marino, L. 2019. Il restauro di siti archeologici e manufatti edili allo stato di rudere, Didapress, Firenze.

Martone, M., 1928. Storia e leggende di castelli lucani, Erreci, Anzi.

Oteri, A. M., 2009. Rovine. Visioni, teorie, restauri del rudere in architetture, Argos, Roma.

Pane, A., 2018. Dispositivi di collegamento verticale. Conservazione vs Innovazione. L'inserimento di elementi tecnologici in contesti storici, Il Prato, Saonara, 91-106.

Remondino, F., Zhang, L., 2006. Surface reconstruction algorithms for detailed close-range object modeling. IAPRS\&SIS, 36 (3), 117-121.

Sthamer, E., 1914. Die Verwaltung der Kastelle im Konigreich Sizilien unter Kaiser Friedrich 2. und Karl 1. von Anjou, K. W. Hiersemann, Leipzig.

Winkelmann, E., 1888. Acta imperii inedita seculi 13: Urkunden und Briefe zur Geschichte des Kaiserreicichs und des Konigreichs Sicilien: in den Jaren 1198 bis 1273, Verlag der Wagner'schen Universitats-Buchhandulung, Innsbruck. 